\title{
Consecuencias del desconocimiento del significado de la terminología de la Danza Clásica
}

\section{Impact of the disregard of the meaning of Ballet terminology}

\author{
Paula De Castro Fernández*, Hervé Ilari** \\ *CSDMA, **EPDCyL
}

\begin{abstract}
Resumen
A través de esta reflexión sobre la enseñanza de la Danza Clásica se ha reconocido y puesto en evidencia el empobrecimiento y las derivaciones que el vocabulario de la Danza ha sufrido a través de las épocas, y especialmente en el siglo XX, así como sus consecuencias en el alumnado. Si bien es cierto que la utilización de una terminología unificada facilita la transmisión de la enseñanza de la danza a nivel mundial, el déficit de conocimientos del profesorado puede conllevar tanto una abreviación extrema, una interpretación incorrecta, como incluso la exención del sentido original del término.

Palabras clave: danza, terminología, enseñanzas artísticas, lengua francesa
\end{abstract}

\begin{abstract}
Through this analysis of the teaching of classical dance has been recognized and put into evidence the impoverishment and the derivations that the vocabulary of the dance has undergone through the ages, and especially in the 20th century, as well as its impact on students. While it is true that the use of a unified terminology facilitates the transmission of the dance education worldwide, the shortage of teachers expertise can lead to an extreme abbreviation, an incorrect interpretation, as even the exemption from the original sense of the term.

Keywords: dance, terminology, art education, french language
\end{abstract}

\section{Introducción}

En el trabajo que sigue, hemos intentado conectar la interpretación del movimiento bailado y el desarrollo y utilización del vocabulario específico empleado y sus orígenes. En efecto, antes de poder interpretar una danza o encarnar un rol, el bailarín debe conocer los pasos de base, sus orígenes, su significado, el objetivo de su utilización, primero para comprender las motivaciones del coreógrafo y después para poder retranscribir con la mayor exactitud. Es en este sentido que el vocabulario de la Danza Clásica se ha desarrollado, para interpretar el movimiento con la mayor fidelidad, para calificarlo, explicarlo, transmitirlo y compartirlo. Podemos, pues, constatar la estrechez de las relaciones entre interpretación y pedagogía.

\section{En busca del origen}

En 1989, durante la elaboración del D. E. (Diplôme d'État) y del C. A. (Certificat d'Aptitude) de profesor de Danza por el Ministerio de Cultura de Francia, y de sus formaciones respectivas, el vocabulario de la danza académica fue revisitado con el objetivo de respetar el pasado y de conseguir una uniformización (Ministère de la Culture et de la Communication, 2002). Evidentemente, esta tentativa de federar los diferentes enfoques y utilizaciones del vocabulario de la danza académica se encontró con numerosos desacuerdos y conflictos en cuanto a la nomenclatura; cada experto reivindicaba para sí el verdadero origen o el verdadero sentido de cada término y expresión de este vocabulario con varios siglos de antigüedad, y que ha sufrido tantos cambios y evoluciones como intervinientes de la danza pueden existir. Como cualquier otra elección, comporta defensores y retractores, pero la propuesta establecida en ese momento constituye una guía de base interesante, evolutiva, pero flexible en cierta medida. Podemos citar como ejemplo de esta nomenclatura la configuración de los saltos, que se han repertoriado de la siguiente forma:

-Saltos de dos pies sobre dos pies: Soubresaut

-Saltos de dos pies sobre un pie: Sissonne

-Saltos de un pie sobre dos pies: Assemblé

-Saltos de un pie sobre el mismo pie: Temps levé

-Salto de un pie sobre el otro: Jeté

Otro ejemplo que deformaba el concepto de las posiciones establecidas por C. L. Beauchamps, es la rectificación de la desviación de la utilización de términos como "a la segunda" o "en arabesque". Se ha hecho una amalgama entre posición y colocación espacial y corporal para indicar, en esos dos ejemplos, el lado del cuerpo y detrás, respectivamente. Esta transformación realizada por un gran número de profesores de todos los orígenes a través del tiempo, se encuentra igualmente reflejada en el Dictionnaire Larousse de la Danse (Le Moal, 1999) en los párrafos referentes a las explicaciones de los pasos de la danza, demostrando que esta derivación, que forma ya parte de los hábitos colectivos, se encuentra incluida en un diccionario. 
A través de esta reflexión sobre la enseñanza de la Danza se ha reconocido y puesto en evidencia de forma unánime, el empobrecimiento o las derivaciones que el vocabulario de la Danza ha sufrido a través de las épocas, y sobre todo en el siglo XX. Mientras que se había desarrollado con el objetivo de interpretar el movimiento calificándolo con detalle, aportando información completa sobre la ejecución misma del movimiento, del espacio, la localización corporal, el desplazamiento, la dinámica, la velocidad, la relación con la música en el tempo y en el contenido rítmico, los efectos interpretativos deseados, por no citar más que éstos, se encuentra hoy, la mayoría de las veces, resumido a una sola palabra o expresión despojada de sentido, o aún peor, cuyo sentido es erróneo. Por desconocimiento, por pereza, incomprensión de la lengua francesa o por sinergia de hábito por la parte de los transmisores, la esencia misma del movimiento desaparece entonces para dar lugar a indicaciones de posiciones, de posturas corporales fijas y rígidas, en la transmisión a la imaginación del receptor. La idea preconcebida, pues, vehiculada y transmitida de forma que la Danza Académica (o Clásica) se vea reflejada de tal manera, se encuentra en el extremo opuesto de la esencia del movimiento, de la danza y por tanto, de su interpretación. Por otra parte, la transformación de la palabra y de su significado, y su uso erróneo, desarrollado en el extranjero o por extranjeros, cuyo conocimiento de la lengua francesa es poco o nada dominada, ha podido observarse a través del tiempo, y ha producido un cierto número de derivaciones, tanto en el significado como en la ejecución (como sisol*, en lugar de sissonne, rond de jam* en lugar de rond de jambe, grand versé* en lugar de renversé, coupé designando la posición en el cou-depied en lugar de una acción).

Se produce poco a poco, por las causas citadas, un olvido casi colectivo de la razón de la existencia y del desarrollo del vocabulario de la danza, que se ha transformado en una especie de vocabulario de codificación desprovisto de sentido. Necesitamos, pues, volver al nacimiento de éste y a sus orígenes, para comprender mejor el sentido y las razones interpretativas de su elección y de su utilización.

\section{De la interpretación al paso, del paso al vocabulario}

A la hora de ejecutar una coreografía o de interpretar un rol, el bailarín va a encontrarse confrontado al examen y la asimilación de las diferentes informaciones que va a recibir o buscar. Los coreógrafos, los maestros de ballet, los repetidores o los profesores van a tener que aportarle todas las indicaciones posibles y necesarias tanto corporales, como espaciales, direccionales, musicales pero también sobre la estética, la imagen, la plástica, aun así sobre la psicología del personaje a encarnar.

Todas estas indicaciones, añadidas a la experiencia misma del bailarín que las recibe, así como a su capacidad de análisis más o menos profundizada, van a desarrollar y forjar su futuro grado de comprensión y de interpretación de dichas informaciones. Solo a partir de este proceso se puede comenzar realmente el trabajo interpretativo del bailarín, de la coreografía o del rol a encarnar.

Las características demandadas por un coreógrafo sobre la manera de desplazarse, andar, saltar, girar, portar, mirar, ser, van a determinar la interpretación de la coreografía o del rol a encarnar, y van modelar los pasos empleados según estas necesidades. Este proceso de "análisis funcional del movimiento bailado" va a ser establecido como herramienta, con el fin de tocar la imaginación y la emoción humanas con sus características, tanto del intérprete en el momento de la creación y de la reproducción, como del público durante la recepción de la obra.

A lo largo de los siglos, los actores del mundo de la danza van a interesarse por el cuerpo y por sus posibilidades siempre incrementadas, otros por el simbolismo de los movimientos, otros por la arquitectura de los desplazamientos en el espacio, otros por la mímica o la pantomima, pero todos con una misma constante: enriquecer el vocabulario de la danza utilizando los calificativos más variados y precisos con el fin de interpretarlo lo mejor posible. En la obra: Coreografía o el arte de describir la danza por caracteres, figuras y signos demostrativos, de Raoul Auger Feuillet, (1700), donde se retoman los conceptos de C. L. Beauchamps (Maestro de baile de Louis XIV), el autor nos propone ya 11 formas corporales utilizadas en el mundo de la danza en esta época:

Posiciones: es lo que marca los diferentes sitios donde se puede posar los pies bailando; "los Pasos": es lo que anda de un lugar a otro; el "Plier": es cuando se pliegan las rodillas; el "Elevado": es cuando se extienden las rodillas; el "Saltado" : es cuando nos elevamos en el aire; la "Cabriole": es cuando saltando, las piernas baten la una contra la otra; el "Tombê": es cuando el cuerpo es fuera de su equilibrio, y cae por su propio peso; el "Glissé": es cuando el pie andando resbala por el suelo; el "Tourné": es cuando se gira hacia un lado o hacia el otro; la "Cadencia ": es el conocimiento de las diferentes medidas, y de los lugares más marcantes en el aire; la "Figure": es seguir un camino trazado con arte (Feuillet, 1979, pág. 2).

En estos ejemplos ya se pueden encontrar indicaciones sobre el cuerpo, el espacio, la relación con la música, el modo de hacer movimientos.

R. A. Feuillet nos indica igualmente posibilidades de ejecutar y de calificar un paso con la finalidad de interpretarlo, describiendo así el Pas droit, el Pas ouvert, el Pas rond (futuro rond de jambe), el Pas tortillé, el Pas battu, pero también el Pas plié, el Pas élevé (futuro relevé), el Pas sauté, el Pas cabriolé (futuro entrechat), el Pas tombé, el Pas glissé (futura glissade).

Nos informa igualmente sobre los diferentes modos de posar el pie en tierra así como sobre el desplazamiento o no del peso del cuerpo, ya el pas tourné (futura pirouette) será disecado en cuarto de giro, medio giro, tres cuartos de giro y giro entero. Habla luego sobre los saltos que ya son repartidos en categorías: "Salto de ambos pies a la vez, Salto andando un pie solo“. El paso saltado se hará con respecto a él de dos maneras: "saltado y recaído sobre la misma pierna que anda, y saltado y recaído sobre la otra pierna que la que anda“(Feuillet, 1979, pág. 15).

Los grandes maestros van a aportar sus propias contribuciones en forma de novedades acorde a sus 
diferentes enfoques de la danza; se puede así citar a J. G. Noverre, gran dramaturgo que antepone la interpretación al virtuosismo técnico, o a A. Vestris, gran virtuoso técnico y profesor, entre otros, de A. Bournonville. Y se podrían citar muchos más, todos ellos introductores de importantes aportaciones a lo largo de los siglos. En esta investigación de la interpretación del movimiento, un gran teórico de principios del s. XX, Rudolf Laban (1994), irá todavía más lejos tanto en el análisis del movimiento como en su escritura, proponiendo un vocabulario de términos de acción adaptado para calificar el movimiento. Indicará, por ejemplo, cinco unidades rítmicas del movimiento: impuls (impulsión con deceleración), impact (aceleración para acabar con un impacto), continue (siempre con la misma velocidad), swing (aceleración y deceleración dependiente de la atracción terrestre), rebound (aceleración, impact, deceleración dependiente de la atracción terrestre). Evidentemente, los trabajos y las aportaciones de R. Laban son mucho más importantes, tanto en la calidad del contenido como en la multitud de informaciones, y han sido objeto de numerosas investigaciones.

\section{Ejemplos terminológicos}

Glissade. "Dégagé glissé de la pierna libre con transferencia de peso, seguido de un cierre en quinta posición delante o detrás, con o sin cambio de pie". (Le Moal, 1999, p. 742).

Paso de recorrido y de conexión, la glissade permite desplazarse lateralmente. Puede hacerse en serie y sirve de preparación de numerosos pasos.

Conocida desde el siglo XVII, figura en F. De Lauze (1623) y M. Mersenne (1975).Pero su contenido cinético no nos es revelado más que por P. Rameau (1748), para quien es un coupé abierto de lado y cruzado por delante o por detrás. Una sucesión de dos glissades era necesaria para llenar un compás musical, lo que confirma la rapidez con la cual tenía que ser ejecutado. El "pas glissé" descrito por R. A. Feuillet (1979), sirve en la construcción de numeroso pasos, sostenidos para la mayoría, y del tiempo de corriente.

Salto de un pie sobre el otro, de la familia del jeté, por tanto. Puede ser lenta o rápida, pequeña o grande, pero sirve siempre, o casi siempre, como preparación a otro paso. Además, su dinámica es constante; debe dar la sensación de "resbalar", "deslizar", de desplazamiento paralelo al suelo, por tanto. El objetivo de dinámica buscado podría identificarse con la imagen de un patinador sobre el hielo. De nuevo, el término utilizado para calificar una acción proviene de la interpretación del movimiento ejecutado.

Assemblé. En la ejecución del assemblé, la pierna libre sale antes el salto y se junta a la otra antes de caer ambas en tierra en una posición cerrada. Pueden realizarse dessus, dessous, battus, soutenus (fermés sur pointes o demi-pointes), doubles, en tournant, con o sin cambio de pie. En serie, dessous o dessus, se denominan assemblés en remontant o en descendant, una expresión tomada de la escuela francesa por referencia a la escena inclinada de la Ópera de París. Tendrán una dinámica diferente si se ejecutan à la hauteur como grands assemblés. El assemblé porté se realiza con desplazamiento lateral. El assemblé failli es un paso de conexión y preparación para el siguiente, y se termina por un posé en segunda o en cuarta posición con la pierna que ha realizado el dégagé. Según Le Moal (1999), el paso assemblé, practicado desde el siglo XVII, mencionado entonces primero como verbo, luego en forma de participio, se hace en tierra o en el aire y cierra siempre en primera posición". Es uno de los pasos fundamentales de la Belle Danse, y se encuentra a menudo a la finalización de otros pasos, como es el caso del pas de gavotte. Ya sea à terre (assemblé soutenu) o en l'air saltado con o sin desplazamiento, pequeño o grande, la acción de assembler (juntar) las piernas es primordial para la dinámica del movimiento. La acción de assemblage de las piernas en la ascensión del salto facilitará el efecto buscado a través de esta dinámica. Pero el assemblé es también la capacidad de calcar el cuerpo a una posición determinada, como es el caso de un assemblé en $2^{\mathrm{a}}$ o en $4^{\mathrm{a}}$ posición, partiendo del principio que el assemblé es un salto de un pie a dos pies. Estos aspectos son poco o nada conocidos por una gran mayoría de docentes en danza clásica, lo que conlleva un déficit en la calidad de ejecución del paso en cuestión, desvirtuando su esencia e intencionalidad primigenias.

\section{Conclusiones}

Como hemos podido constatar, el vocabulario utilizado en la Danza Académica es tan rico como ecléctico. Que se haya desarrollado y enriquecido a través de los siglos con las aportaciones de diferentes intervinientes del mundo de la Danza, incorporando a veces términos prestados de otras disciplinas (música, equitación, teatro, esgrima...), o que sea objeto, simplemente, del análisis funcional del movimiento, y en nuestro caso, del movimiento danzado, el vocabulario no ha cesado de evolucionar para interpretarlo.

Las principales consecuencias del desconocimiento del verdadero significado de la nomenclatura dancística, identificadas tras años de observación en conservatorios, escuelas y compañías de danza de varios continentes, son :

-Falta de información concreta y completa en el momento de la ejecución del paso;

-Consecuentemente, orden neurofísica errónea, que dificulta y/o impide el óptimo desarrollo muscular;

-Imprecisión corporal, espacial, dinámica, rítmica y melódica;

-La incomprensión del vocabulario calificativo impide la interpretación idónea del paso o del conjunto de pasos, conduciente a una creciente restricción interpretativa ;

-Modificaciones significativas del paso original;

-Mutaciones y empobrecimiento del vocabulario dancístico;

-Dificultades en la enseñanza y transmisión de la técnica de la danza clásica.

De C. L. Beauchamps a R. A. Feuillet, de J. G. Noverre a A. Vestris, de A. Bournonville a M. Petipa o de R. Laban a S. Lifar, de la utilización del pas coupé al pas cabriolé, de la pantomima a la virtuosidad técnica, de la danse de cour a la danza neoclásica, del swing al décalé, el movimiento danzado vehicula informaciones interpretativas con el objetivo de retranscribir la 
condición y las emociones humanas. Evidentemente, esta interpretación del movimiento es subjetiva y varía según los individuos. Por ello, conforma lo propio del Arte; no obstante, la Danza Académica ha resistido tras casi cuatro siglos de historia e invadido el mundo entero, confirmando, pues, su universalidad, y el mensaje interpretativo que consigue comunicar.

Es por lo tanto nuestra responsabilidad como docentes, perpetuar el Arte de la Danza respetando y sublimando todos sus aspectos (entre ellos, el vocabulario), cuyo valioso legado hemos recibido en herencia de nuestros pares y maestros a lo largo de los siglos.

\section{Referencias}

De Lauze, F. (1623). Apologie de la danse et la parfaicte methode de l'enseigner tant aux Cavaliers qu'aux Dames. París: (s. http://www.libraryofdance.org/manuals/1623-LauzeApologie_(BNF).pdf

Feuillet, R. A. (1979). Chorégraphie ou l'art de décrire la danse par caractères, figures et signes démonstratifs. Hildesheim: Georg Olms.

Laban, R. (1994). La Maîtrise du mouvement. Arles: Actes sud.

Le Moal, Ph. (dir.). (1999). Dictionnaire de la danse. París: Larousse.

Mersenne, M. (1975). Harmonie Universelle. París: CNRS Éditions.

Ministère de la culture et la communication. (2002). Diplôme d'Etat de professeur de danse. Loi du 10 juillet 1989. París: Direction de la musique de la danse du théâtre et des spectacles.

Rameau, P. (1748). Le Maître à danser. París: Rollin fils. 